The Journal of

Thoracic and Cardiovascular

Surgery

Vol 125, No. 6, June 2003

\title{
Another chapter in an enlarging book: Repair degenerative mitral valves
}

\author{
David H. Adams, MD \\ Farzan Filsoufi, MD
}

\author{
See related article on page \\ 1350.
}

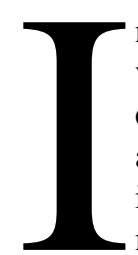

n this issue of the Journal, Gillinov and colleagues ${ }^{1}$ provide us with another valuable contribution in the field of mitral valve repair from their large experience at The Cleveland Clinic Foundation available for sophisticated and cutting-edge (ie, Eugene Blackstone) statistical analysis. The superiority of mitral valve repair over replacement in patients with degenerative mitral valve disease is now widely held to be true. It would be surprising to see a single hand raised in a medical audience today if you asked, "Who would prefer to have his or her own valve replaced instead of repaired?" Intuitively it is attractive to keep the parts you were born with. Other potential advantages including better preservation of left ventricular function, avoidance of long-term anticoagulation (mechanical valves) or reoperation (bioprosthetic valves), and improved survival all favor mitral valve repair as the gold standard. ${ }^{2-5}$ Should the need for a concomitant coronary artery bypass procedure change the paradigm? This is the important question addressed by Gillinov and associates in their analysis of 679 patients with degenerative mitral valve disease and ischemic heart disease undergoing coronary bypass grafting and mitral valve surgery (repair or replacement). It is not surprising that their data provide further confirmation of the superiority of mitral valve repair over replacement in terms of survival, the only end point examined. Impressively, the benefit of mitral valve repair in patients with degenerative mitral regurgitation was noted as early as 2 years after the surgical procedure. This important observation reinforces that the necessity for coronary bypass grafting should not influence our determination to repair rather than replace a degenerative mitral valve.

The authors were challenged by the retrospective nature of their analysis, which included patients undergoing surgery over a 3-decade span: (1) Valve replacements were more prevalent in the early phase of the study, whereas most of the valve repairs occurred after 1990. (2) Likewise, the use of the internal thoracic artery was much more common in later patients in their series, who were also more likely to receive a valve repair. (3) Both replacement and repair procedures underwent significant evolution during the study period. For example, chordal-sparing techniques in the valve replacement group became routine in the late 1980s, but this was not specifically determinable in individual patients. Similarly, valve repair techniques evolved over time, and repairs in their most recent experience were surely improved by the use of annuloplasty prosthetic rings as opposed to annuloplasty using bovine pericardium or non-annuloplasty techniques. (4) Myocardial preservation techniques also evolved and were surely more effective in the later era. (5) The understanding of the pathophysiology of mitral regurgitation and definition of degenerative mitral valve regurgitation also evolved over the study period. 

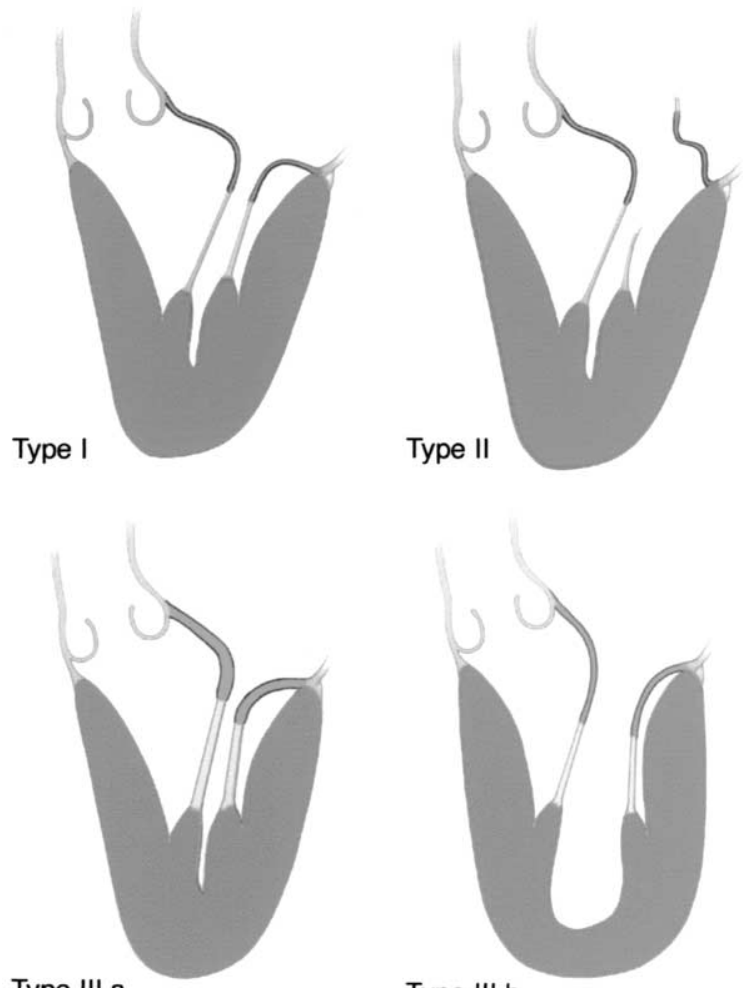

Type III a

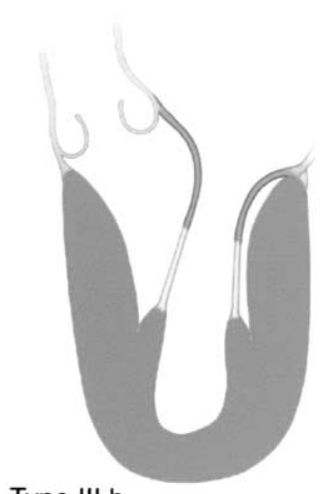

Type III b

Figure 1. Carpentier's functional classification is based on the opening and closing motions of the mitral leaflets. Type I has normal motion of the leaflets and mitral regurgitation is on the basis of the leaflet perforation or annular dilatation. In type II dysfunction (increased leaflet motion) the free edge of the leaflet travels above the plane of the mitral annulus during systole due to chordal elongation or rupture. Type Illa dysfunction implies restricted opening leaflet motion during diastole and systole due to rheumatic changes. Type Illb dysfunction correlates to restricted leaflet motion during systole secondary to papillary muscle displacement.

Craig Miller ${ }^{6}$ has previously provided an excellent editorial comment in the Journal regarding the statistical challenges and tools necessary to address the mitral valve repair versus replacement comparison for patients in retrospective nonrandomized trials. Many of the issues Miller discussed are relevant to this article, and we suggest those interested in the nuances of the statistical art refer to it. In the current study by Gillinov and associates, time period was used as a surrogate for chordal-sparing techniques in an attempt to assess the impact of this advance in the replacement group (no advantage was statistically realized.) The potential impact of myocardial protection and the evolution of mitral repair techniques were unfortunately not examined by the authors. For the remainder of issues mentioned previously, there is a lot of "Gene-speak," and the authors used sophisticated techniques including multivariable propensity matching and multivariable, multiphase hazard function analysis to examine factors associated with valve repair or replacement and risk factors for death. ${ }^{7,8}$

It is interesting to note the confusing terminology, typical of the literature, used by the authors to define degenerative mitral valve disease. Carpentier9 has affectionately referred to the usage of multiple terminologies to identify patients with degenerative disease as the "Babel syndrome," for example, "myxomatous degeneration," "floppy leaflets," "billowing leaflets," and "leaflet prolapse." It is much more useful to think about mitral valve disease in terms of his pathophysiologic triad that includes the type of valve dysfunction, the lesions, and the etiology. ${ }^{9}$ Valve dysfunction correlates to Carpentier's functional classification (see Figure 1). Patients with degenerative mitral valve disease most commonly have type II dysfunction, which corresponds to the overriding of the free edge of the leaflet above the plane of the mitral annulus during systole (leaflet prolapse). Associated annular dilation is a common finding in these patients; however, isolated annular dilatation (type I dysfunction) with normal motion of both leaflets has also been reported. Of note, we have not observed leaflet restriction (type III dysfunction) in patients with degenerative disease due to an "abnormal chordal mesh" of the posterior leaflet as described by the authors. Lesions most commonly responsible for valve dysfunction in degenerative mitral valve disease include chordal elongation and chordal rupture. Etiologies of degenerative mitral valve disease include fibroelastic deficiency (first described by Carpentier), Barlow disease (characterized by myxoid degeneration), and Marfan disease. ${ }^{10}$ Fibroelastic deficiency is most common in elderly patients with a relatively short history of valve dysfunction. Intraoperative analysis typically shows transparent leaflets with no excess tissue except in the prolapsing segment, and elongated, thin and frail, often ruptured, chordae. The annulus is often dilated, and may be calcified. In contrast, Barlow disease appears early in life, and patients typically have a long history of a systolic murmur. The valve leaflets are typically thick with marked excess tissue. The chordae are thickened, elongated, and may be ruptured. Papillary muscles are also occasionally elongated. The annulus is dilated and sometimes calcified. Marfan disease with mitral regurgitation is characterized by excess leaflet tissue, which may be thickened (without myxoid degeneration), and a dilated annulus that is rarely calcified. In some patients with degenerative mitral valve disease, the exact etiology of valvular regurgitation remains undetermined.

The importance of a uniform method to identify patients with mitral valve disease is best exemplified by comparing the current study by Gillinov and colleagues ${ }^{1}$ in patients with degenerative mitral valve disease and coexisting coronary artery disease with another report by this group ${ }^{11}$ describing the durability of mitral valve repair in patients 
with isolated degenerative mitral disease. In the current series (mean age 67 years, $73 \%$ male), annular dilatation is not reported as an isolated mitral valve pathologic finding. In contrast, the authors noted annular dilatation as the primary pathologic lesion in $16 \%$ of 1072 patients (mean age 58 years, $65 \%$ male) with degenerative mitral valve disease undergoing isolated mitral valve repair between 1985 and 1997. It is unlikely that the mitral degenerative process varies in patients with or without coexisting coronary artery disease or that the mean age difference between the two series explains the observed findings. We suspect a more plausible explanation is a variance in their pathologic methodology over time. We also take issue with the concept presented by the authors "that elderly patients have more advanced degenerative disease with more prolapse than do younger patients with isolated mitral valve degeneration."1 In our experience Barlow disease and Marfan disease are usually associated with severe mitral regurgitation due to multiple prolapsing leaflet segments and are more prevalent in younger patients undergoing mitral valve surgery.

It is important to emphasize that the authors were very careful to exclude patients with ischemic mitral regurgitation in their study. Patients with this condition usually have type IIIb dysfunction with leaflet restriction in systole, due most commonly to papillary muscle displacement from ventricular dilatation. Their long-term prognosis is significantly worse than that of patients with degenerative mitral valve disease. ${ }^{12-15}$ In the future, we advocate a more uniform adoption in the literature of classification of patients with mitral valve disease according to valve dysfunctions, lesions, and etiologies of disease. These precise distinctions are relevant because the repair strategy depends on valve dysfunction and lesions, whereas long-term prognosis depends on etiology.

As is the case with many retrospective studies, some of the reported findings are not particularly relevant since they do not reflect current practice patterns. For example, the authors observed replacement was more likely in older patients with degenerative mitral valve disease. The safety and efficacy of mitral valve repair in patients with advanced age is now well documented in the literature ${ }^{16,17}$ Similarly, it is a safe bet that bileaflet prolapse is no longer associated with a significantly increased incidence of replacement in skilled mitral valve repair centers like The Cleveland Clinic. ${ }^{2,3,11}$ One final caveat: we strongly disagree with the concept of an algorithm to choose mitral valve surgical strategy as presented by the authors in Figure 4 and Appendix 2. "Replacement benefit" is an oxymoron in patients with degenerative mitral valve disease. The only consideration in degenerative mitral regurgitation for repair or replacement should be the surgeon's ability to achieve a successful repair. There may be isolated patients with advanced left ventricular dysfunction or other comorbidities in whom the survival benefit of a mitral valve repair is not obvious; however, it is important to emphasize the authors did not assess the quality of valve repair, quality of life, left ventricular function over time, valve-related complications, valve durability, or reoperation in this study.

The methodology of data analysis was complex, and the authors deserve substantial praise for a statistical tour de force to demonstrate the benefit of mitral valve repair in patients with degenerative disease and concomitant coronary artery disease. They have provided further evidence that our patients deserve our best effort to preserve the native mitral valve whenever possible.

\section{References}

1. Gillinov AM, Faber C, Houghtaling PL, Blackstone EH, Lam BK, Diaz R, et al. Repair versus replacement for degenerative mitral valve disease with coexisting ischemic heart disease. J Thorac Cardiovasc Surg. 2003;125:1350-62.

2. Braunberger E, Deloche A, Berrebi A, Abdallah F, Celestin JA, Meimoun P, et al. Very long-term results (more than 20 years) of valve repair with Carpentier's techniques in non-rheumatic mitral valve insufficiency. Circulation. 2001;104(Suppl I):I8-11.

3. Mohty D, Orszulak TA, Schaff HV, Avierinos JF, Tajik JA, Sarano ME. Very long-term survival and durability of mitral valve repair for mitral valve prolapse. Circulation. 2001;104(Suppl I):I1-7.

4. Enriquez-Sarano M, Schaff HV, Orszulak TA, Tajik AJ, Bailey KR, Frye RL. Valve repair improves the outcome of surgery for mitral regurgitation: a multivariate analysis. Circulation. 1195;91:1022-8.

5. Lee EM, Shapiro LM, Wells FC. Superiority of mitral valve repair in surgery for degenerative mitral regurgitation. Eur Heart J. 1997;18: 655-63.

6. Miller DC. Ischemic mitral regurgitation redux-To repair or to replace? J Thorac Cardiovasc Surg. 2001;122:1059-62.

7. Blackstone EH. Breaking down barriers: helpful breakthrough statistical methods you need to understand better. J Thorac Cardiovasc Surg. 2001;122:430-9.

8. Blackstone EH. Comparing apples and oranges. J Thorac Cardiovasc Surg. 2002;123:8-15.

9. Carpentier A. Cardiac valve surgery-the "French correction." J Thorac Cardiovasc Surg. 1983;86:323-37.

10. Carpentier A, Fabiani JN, Relland J, d'Allaines C, Piwnica A. Reconstructive surgery of mitral valve incompetence: ten-year appraisal. J Thorac Cardiovasc Surg. 1980;79:338-348.

11. Gillinov AM, Cosgrove DM, Blackstone EH, Diaz R, Arnold JH, Lytle $\mathrm{BW}$, et al. Durability of mitral valve repair for degenerative disease. J Thorac Cardiovasc Surg. 1998;116:734-43.

12. Cohn LH, Rizzo RJ, Adams DH, Couper GS, Sullivan TE, Collins JJ, et al. The effect of pathophysiology on the surgical treatment of ischemic mitral regurgitation operative and late risks of repair versus replacement. Eur J Cardiothorac Surg. 1995;9:568-74.

13. Grossi EA, Goldberg JD, LaPietra A, Ye X, Zakow P, Sussman M, et al. Ischemic mitral reconstruction and replacement: comparison of long-term survival and complications. J Thorac Cardiovasc Surg. 2001;122:1107-24.

14. Gillinov AM, Wierup PN, Blackstone EH, Bishay ES, Cosgrove DM, White $\mathrm{J}$, et al. Is repair preferable to replacement for ischemic mitral regurgitation? J Thorac Cardiovasc Surg. 2001;122:1125-41.

15. Adams DH, Filsoufi F, Aklog L. Surgical treatment of the ischemic mitral valve. J Heart Valve Dis. 2002;11(Suppl 1):S21-5.

16. Jebara VA, Dervanian P, Acar C, Grare P, Mihaileanu S, Chauvaud S, et al. Mitral valve repair using Carpentier techniques in patients more than 70 years old: early and late results. Circulation. 1992;86(5 Suppl): II53-9.

17. Grossi EA, Zakow PK, Sussman M, Galloway AC, Delianides J, Baumann $\mathrm{G}$, et al. Late results of mitral valve reconstruction in the elderly. Ann Thorac Surg. 2001;71:1752-3. 